\title{
KNOWLEDGE, PRACTICE AND USE OF PESTICIDES AMONG COMMERCIAL VEGETABLE GROWERS OF DHADING DISTRICT, NEPAL
}

\begin{abstract}
P. Shrestha ${ }^{1}$, P. Koirala ${ }^{2}$ and A. S. Tamrakar ${ }^{2}$
ABSTRACT

A field study was conducted to evaluate knowledge, practice and use of pesticides among thirty commercial vegetable growers of Dhading district of Nepal. More than four in five were using pesticides and more than one third were using it for more than six years. Nearly half of them spray pesticides five to six times. More than one-sixth pesticides used were extremely hazardous, which were barred for general agriculture use. Waiting period is less than four days for nearly two-third growers. More than three-forth know the adverse effect of pesticides and nearly half experienced symptoms of health hazards. Majority did not receive any official training on pesticides and nearly one-third doesn't read information available in pesticide label. Nearly half were not using Personal Protective Equipment during pesticide application. Nearly two-third throw pesticide container anywhere after using it. The finding of this study is oriented to the following recommendation: the need for awareness, education and training on the uses of pesticides to the farmers and effective monitoring program for pesticide residues in vegetables.
\end{abstract}

Key words: Awareness, health effects, IPM, pesticides, vegetables

\section{INTRODUCTION}

Fresh vegetables are an essential part of a healthy diet as it is an important source of vitamins and minerals. However, vegetables can also be a source of poisonous toxic substance-pesticides (Knezevic Z. and Serdar M., 2008). Over 1000 compounds may be applied to agricultural crops in order to control objectionable moulds, insects and weeds (Ortelli et al., 2006). Pesticides' striking effort in preventing, crop loss and controlling vectors of diseases have led to their acceptance and expanded use throughout the world (Sharp and Peter 2005 ). However, the potent chemicals for killing pests have elevated anxiety that they are agents of human diseases and environmental pollution. It has been observed that their long term, low dose exposure is increasingly linked to human health effects such as immune-suppression, hormone disruption, diminished intelligence, reproductive abnormalities and cancer (Wiles, Davies and Campbell, 1998). Pesticide residues in food are global problems (Abinash and Singh 2009).

Pesticides classified as being extremely or highly hazardous by FAO and WHO, including barred by some countries, unrelenting used in developing countries (WHO 2003). According to WHO, developing countries use about twenty-five percent of the pesticides in the worlds, and the use is in increasing trend. This intrinsically dangerous technology is being promoted in a setting without technical and human resources to control it properly.

Agriculture work is one of the most prevalent types of employment in the world. Nearly 50 percent of the world labor is employed in agriculture and they carry significant risk for development of pesticide risk (Das et at., 2001). Global warming will create a promising threat in pesticide safety in foods and human health (Koirala et al., 2009). The potential impact of climate change on pesticide safety is a widely debated and investigated issue (Bailey, 2008).

\footnotetext{
${ }^{1}$ College of Applied Food and Dairy Technology, Kathmandu Nepal

${ }^{2}$ Tribhuvan University, Kathmandu Nepal
} 
Chemical pesticides for the first time were commenced in Nepal in 1952 when Paris green Gammexane and Nicotine sulphate were imported from USA solely for malaria control program- (Koirala et al., 2009). The sequential order of different groups of pesticides introduced in Nepal is: 1950s - organochlorines; 1960s - organophosphates; 1970s carbamates; 1980s - synthetic pyrethroids. (Manandhar, 2007). Now, Nepal import pesticides from six different countries-India, China, Malaysia, Singapore, Italy and Japan (PRMD 2009). Local manufacture is in small quantities. At present, there are four industries that have been registered to manufacture and formulate pesticides. Pesticide Registration and Management Division (PRMD) under the Ministry of Agriculture and Cooperatives is responsible for registration of pesticides as well as providing license for import and distribution of pesticides to retailers and wholesalers according to Pesticide Act 1991. By the end of 2010, Fifty two certified importers are involved in marketing of seventy six registered common pesticides in three hundred and forty two trade names. Majority of registered pesticides are insecticides (36/76)- followed by fungicides (18/76) (Koirala et al., 2009).

The pesticide import data for the year 2006 is $131285 \mathrm{~kg}$ (based on active ingredient) and $338365 \mathrm{~kg}$ based on formulation) and for the year 2007 is $347495 \mathrm{~kg}$ (based on a.i) and $762543 \mathrm{~kg}$ (based on formulation). The import data for the year 2007 is almost 250\% higher compared to the year 2006 (PRMD, 2009). There is no clear drift of import and use of pesticides. Also there is possibility of an open border trading of commonly used pesticides and some of the banned pesticides such as DDT and BHC. It is somewhat difficult to document the amount of illegal trading and thus the size of such trading has not been reflected in the public data so far.

In recent years, there are different pesticides used erratically, which is pretty common in Nepal. Endosulfan is used in ponds, streams and rivers for killing fishes. This has created potential danger for extinct of the most commonly and in large quantities available native species of fishes. Similarly, endosulfan is also used to attain polished appearance in vegetables such as tomato, brinjal, mustard leaves. Blend of pesticides is also applied in different vegetables and tea. Some insecticides are also applied to fish surface to keep flies away from it during display in shop. Almunium phosphide is used for fumigation in open mud beans adjacent to bed room. Use of date expired pesticides and throwing pesticide containers at public places is a wide-ranging practice. Pesticide treated grains is given for nourishing horses (Manandhar, 2007).

Nepal has a marvelous opportunity for producing vegetables as diverse agro-eco-zone favors both season and off-season varieties. Due to this advantage farmers are encouraged to produce vegetables. Thus production and productivity of vegetables has been increasing significantly for the last decade. Nepal has sell to other countries potential for fresh vegetables and processed products in the international market as well.

Dhading district supply nearly 20 percent of total requirement of vegetables of Kathmandu Valley. Reports suggest that use of pesticides in vegetable in Nepal is higher than other food products (Koirala et al., 2009). No previous research reports are available for pesticide use in vegetables for Dhading district. Therefore, this study aims to know the current situation of pesticide use in vegetables and to investigate knowledge, practice among commercial vegetable growers and use of pesticides in vegetables of Dhading district, Nepal. Field study was made on September to October, 2009.

\section{MATERIAL AND METHODS}

Two Village Development Committee (VDCs) in Dhading district namely Jiwanpur and Kewalpur, which are the major production areas of vegetables, were chosen for the study reason. In one VDC, three wards were selected. In a single ward five households who were involved in commercial vegetable farming were selected. Altogether accounts thirty 
households in two VDCs. The commercial vegetable growers who were occupied in broccoli, brinjal, cauliflower, lady finger and beans growers included under this study. Field survey was made by using structured questionnaire. Data analysis was made using SPSS software.

\section{RESULT AND DISCUSSIONS}

\section{PESTICIDES USERS AND PESTICIDES USED}

A total of thirty households were surveyed during the study. Half $(50 \%)$ of the vegetable grower were literate and majority of them $(70 \%)$ had only primary education. Forty percent work hard daily about 5-9 hours in the vegetable field. Preponderance $(86.6 \%)$ apply pesticides to vegetables. This showed that in the current year the uses of the pesticides in vegetables has increased and is in rising trend. Nearly a half $(46.6 \%)$ applies pesticide $5-6$ times, whereas, nearly one-forth $(23.3 \%)$ use it 3-4 times depending on severity of pest problem in vegetables. It indicates that there is a high frequency of pesticides use in the vegetable that are possibly to increase toxic residue in the vegetable that might pose higher risk to vegetable growers and consumers.

Growers spray insecticides such as Parathion-Methyl (extremely hazardous 'Ia'); Dichlorovas, Carbofuran (highly hazardous 'Ib'); Alphacypermethrin, Chlorpyrifos, Cypermethrin, Deltramethrin, Dimethoate, Endosulfan, Lambda-Cyhalothrin, Profenofos

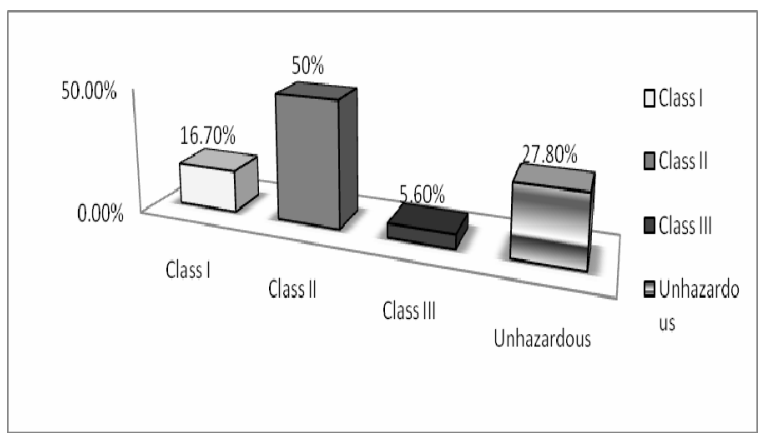

(moderately hazardous 'II'); Dimethipin (slightly hazardous 'III') and fungicides such as Carbendazim, Mancozeb, Maneb and Metalaxyl. Among the pesticides sprayed, half (50\%) of it was of category II, $16.7 \%$ was of category I (Table 1). Use of extremely hazardous pesticides (category I) are banned in the country. The use of these types of high toxic pesticides put health threat for both growers and consumers.

Fig. 1: Types of Pesticide Used according to the Hazardous Level of WHO

\section{KNOWLEDGE OF PESTICIDE}

Majority of growers (93.3\%) did not receive training at all on the use of pesticides. Training helps to get learning on safe handling, storage, disposal and application of pesticides. Therefore, there is a call for promotion of training to growers by government or other development organizations. More than three-forth of vegetable growers $(80 \%)$ have knowledge about the adverse health effects of pesticides, and nearly more than one forth $(26.6 \%)$ do not have the knowledge about the adverse effects. Almost nearly half $(42.9 \%)$ heard about health hazards of pesticides. Among heard, the major source of information was community $(42.9 \%)$. More than forty percent $(43.3 \%)$ think that use of pesticides in future should be decreased in agriculture. Such case suggests that majority want to diminish the use of pesticide and use alternative method that are not dangerous to human and environment. Nearly one-forth (23.3\%) have heard about Integrated Pest Management (IPM). Among heard, a little more than a half $(53.3 \%)$ were using IPM technique. Government of Nepal is promoting IPM to reduce users' dependency on pesticides in agriculture farming. One of the objectives of IPM use is to promote food safety. This study also suggests that the government should promote IPM program for healthier agriculture practices because more than a half of growers now already using IPM technique. 
Table 1: Types of pesticide used

\begin{tabular}{|c|c|c|c|c|c|c|}
\hline S.N & $\begin{array}{l}\text { Trade } \\
\text { Name }\end{array}$ & Common Name & $\begin{array}{l}\text { Phy. } \\
\text { State }\end{array}$ & $\begin{array}{l}\text { Chem. } \\
\text { Type }\end{array}$ & Main Use & Classification \\
\hline 1. & Farsa & Alphacypermethrin 10\% EC & $S$ & PV & Insecticides & class ii \\
\hline 2. & Aerosol & Carbendazim 50\% W.P & $\mathrm{S}$ & & Fungicides & unhazardous \\
\hline 3. & Furan 3G & Carbofuran 3\% g & $S$ & $\mathrm{C}$ & Insecticides & class ib \\
\hline 4. & Durban & Chlorpyrifos 20\% EC & $S$ & $\mathrm{OP}$ & Insecticides & class ii \\
\hline 5. & $\begin{array}{l}\text { a. Surya } \\
\text { Methrin-10 } \\
\text { b. Bicep }\end{array}$ & Cypermethrin 10\% EC & $\mathrm{L}$ & PV & Insecticides & class ii \\
\hline 6. & Super-D & $\begin{array}{l}\text { Cypermethrin 5\%+ } \\
\text { Chloropyriphas 50\% }\end{array}$ & $\begin{array}{l}\mathrm{L} \\
\mathrm{S}\end{array}$ & $\mathrm{PY}+\mathrm{OP}$ & Insecticides & class ii \\
\hline 7. & Desist & Deltramethrin & $\mathrm{S}$ & PY & Insecticides & class ii \\
\hline 8. & $\begin{array}{l}\text { a. Bloom } \\
\text { b. Nuwan }\end{array}$ & Dichorovas $76 \%$ EC & $\mathrm{L}$ & OP & Insecticides & class ib \\
\hline 9. & $\begin{array}{l}\text { a. Rogor } \\
\text { b. Rogorin }\end{array}$ & Dimethipin 30\% EC & I & & Herbicides & class iii \\
\hline 10. & Rogoris & Dimethoate $30 \%$ EC & $\mathrm{S}$ & $\mathrm{OP}$ & Insecticides & classii \\
\hline 11. & $\begin{array}{l}\text { a.Thiodan } \\
\text { b. R-Sulfa }\end{array}$ & Endosulfan 35\% EC & $S$ & OC & Insecticides & class ii \\
\hline 12. & Propel & $\begin{array}{l}\text { Lambda-Cyhalothrin 2.5\% } \\
\text { EC }\end{array}$ & $S$ & PY & Insecticides & class ii \\
\hline 13. & $\begin{array}{l}\text { a. Surya } M-45 \\
\text { b. Uthane } M-45\end{array}$ & Mancozeb 75\%W.P & $S$ & $\mathrm{FC}$ & Fungicides & unhazardous \\
\hline 14. & Manex & Maneb & $\mathrm{S}$ & C & Fungicides & unhazardous \\
\hline 15. & $\begin{array}{l}\text { a. Targmil } \\
\text { b. Kriiaxyl Mz } \\
\text { 72\%WP }\end{array}$ & $\begin{array}{l}\text { Metalaxyl } 8 \%+ \\
\text { Mancozeb0.4\% wp } \\
\text { Metalaxyl } 8 \%+\text { Mancozeb } \\
64 \% \text { W.P }\end{array}$ & SS & $\mathrm{FC}$ & Fungicides & unhazardous \\
\hline 16. & Devithion $^{\text {Th }} 50$ & Methyl Parathion 50\% EC & $\mathrm{L}$ & OP & Insecticides & class ia \\
\hline 17. & Antirot & $\begin{array}{l}\text { Mono-p\% Potassium } \\
\text { Phosphite }\end{array}$ & $S$ & $\mathrm{FC}$ & Fungicides & unhazardous \\
\hline 18. & Current & Profenofos $50 \%$ EC & $\mathrm{L}$ & OP & Insecticides & class ii \\
\hline
\end{tabular}

PRACTICE OF PESTICIDE HANDLING

Pesticides label hold different information related to safety measures to be taken while using. About one-third (33.3\%) read label information, however, only one-fifth $(16.6 \%)$ follow the advice provided in the label.

Almost half of the vegetable growers mix the pesticides with their bare hands and only about one-sixth $(16.6 \%)$ mix in a safer way by wearing gloves. Many pesticides users are highly exposed to dermal exposure due to unsafe mixing practice resulting acute and chronic health hazards. Similarly, there is a need of determination of wind before the application of pesticides. Nearly three fourth of the vegetable growers $(76.6 \%)$ determine the wind direction before spraying while the rest $(23.4 \%)$ do not. Majority of the pesticide users (76.6\%) re-enter the field within short interval 0-4 days after the application of the pesticide, whereas, 24.2 percent of the vegetable grower re-enter at an interval of 5-9 days. Entrance results a greater risk of inhalation, dermal exposure, eye exposure and cause significant health hazards due to exposure of pesticide. Toxic pesticides residue remains in the field after the application of pesticide.

Waiting period is the duration after which the vegetables treated with pesticides can be used. Almost more than a half $(53.3 \%)$ of vegetable growers picks the vegetable at the interval of 0-4 days after the application of pesticides. Less waiting period indicates that 
there is a higher risk of presence of pesticides residue in vegetables which poses higher health risk to vegetable growers as well as consumers.

Practice of maintaining personal hygiene decreases risk of health hazards. Majority of the pesticides sprayers $(84.8 \%)$ do not drink and smoke during pesticide application. Most of the respondents (93.3\%) maintain personal hygiene after pesticide spray. Among them, onefifth $(20 \%)$ take bath which is a good practice and rest $(80 \%)$ maintain by cleaning hands and feet. Nearly forty percent (36.6\%) pesticide users have experienced the symptoms of health hazards. The major problems were eye and skin irritation $(46.6 \%)$ followed by (33.3\%) multiple symptoms such as shortness to breath $(16.6 \%)$ and headache $(10 \%)$. It suggests that pesticide related health problems are common among vegetable growers.

Personal protective equipments include clothes and devices that protect the body from the contact with pesticide during pesticide application. Most of the pesticide users $(66.6 \%)$ didn't use PPE. The reason for not using PPE was lack of knowledge. They don't have affordability and the habit of wearing. Due to unsafe practices, vegetable growers are more vulnerable to expose with toxic pesticides and are in higher health risks as there has been too much use of pesticides with too little or no protection.

\section{PESTICIDES STORAGE, DISPOSAL OF EMPTY CONTAINERS AND WASHING OF APPLICATOR}

Pesticides should be stored in the separate area far away from food, feed, children and pets. Majority of users (86.6\%) store it in a separate place away from food items and medicine. As a result there is less chance of mixing with food and feed. Children or pets also cannot search out it. Pesticides bare containers should be disposed correctly to minimize exposure of it to the environment and human. On the other hand, most of the vegetable growers $(63.3 \%)$ throw the pesticide anywhere they like. They do not dispose properly.

Pesticide applicators should be washed after using it. It should be washed far away from the source of water as it may contaminate the source of water and therefore, destroying aquatic life and wildlife. More than a half of the vegetable growers $(53.3 \%)$ wash pesticide applicator in the source of water like river, streams. One-fifth $(20 \%)$ wash in the tap, and nearly one-forth $(26.6 \%)$ wash away from the source of water. As majority of the vegetable grower wash pesticide applicator in the tap, which is the source of potable water to their home.

\section{CONCLUSION AND RECOMMENDATIONS}

The present study shows extremely hazardous pesticides are being used in vegetables which are banned for normal agriculture use by Government of Nepal. Majority growers did not receive any training on pesticides and IPM techniques. Quite a high figure of growers also experience symptoms associated with pesticides hazards. Most of the growers were not using PPE during pesticide application in vegetables. The results emphasize the need to correct the problems of pesticides. Government regulatory agencies, development organizations, consumers associations should work successfully together work out the problems.

\section{REFERENCES}

Abinash, P. C. and N. Singh, 2009. Pesticide use and application: An Indian scenario. J. Hazard Master, 165(1-3): $1-12$

Arthur L. Frank, 2004. Issues in Agriculture Safety and Health. Annual review of public health vol 25: 225-245

Bailey D., 2008. Climate change impacts on the United States. National Assessment Synthesis Team, US Global Change Research Program, David Suzuki Foundation, Canada.

Das, R., A. Steege, S. Baron, J. Beckman and R. Harrison, 2001. Pesticide related illness among migrant farm workers in the United States Int J. Occup Environ Health Oct-Dec 7(4): 303-12 
Gupta, P. K., 2004. Pesticide use in India. J Toxicoll., 198(1-3): 83-90

Knezevic, Z. and M. Serdar, 2008. Screening of fresh fruits and vegetables for pesticide residues on Croatian Market . J. Food Control doi, 10:1016

Koirala, P., Dahal, N. R., Dhakal, S., Lama, J. P. and U.K. Bhattarai, 2009. An assessment of certain pesticide residues in Nepalese tea. JFSTN, 4:31-32.

Koirala, P., Dhakal, S. and A.S. Tamrakar, 2009. Pesticides and Food Safety Issues in Nepal. The Journal of Agriculture and Environment, 10: 33-36

Manadhar, D.N., 2007. Pesticides in Nepal. SD Manandhar Publisher, Kathmandu.

Ortelli, D., Edder, P. and C. Corvi, 2006. Multi residue analysis of 74 pesticides in fruits and vegetable by liquid chromatography-electro spray-tandem ass spectrometry. Analtica Chimica Acta, 520: 33-45

PRMD, 2009. Status of pesticides consumption in Nepal. Pesticide Registration and Management Division, Lalitpur, Nepal.

Sharp dan, S. and Peter cellas, 2005. Delayed health hazard of pesticides exposure. Annual review of public health, vol 27:312-316

WHO, 2003. Pesticide residue in food. In: International program on chemical safety Joint FAO/WHO meeting on pesticides results evaluations 2002, part 2 Toxicology.

Wiles, R., Davies, K. and C. Campbell, 1998. Over exposed organophosphate insecticides in children's food. Environmental working group, Washington. 